\title{
Ein Magdalénien-Fundplatz in Feldkirchen-Gönnersdorf, Kreis Neuwied ${ }^{1}$ )
}

\author{
Von G. Bosinski, Köln
}

Im März 1968 entdeckte der Architekt K. Richter, Neuwied, in der Baugrube eines Einfamilienhauses in Feldkirchen-Gönnersdorf, Rheinhöhenstraße, einen altsteinzeitlichen Fundplatz. Die neue Fundstelle liegt auf der Mittelterrasse des Rheins gegenüber von Andernach. Auf dem Martinsberg in Andernach war bereits im vorigen Jahrhundert ein vergleichbarer Platz gefunden und 1883 unter der Leitung von H. SchaAfFHAUSEN ausgegraben worden.

Das Profil in Gönnersdorf ist folgendermaßen aufgebaut:

a $0,30 \mathrm{~m} \quad$ Humus

b $1,00-1,50 \mathrm{~m}$ Bims mit einer Britzbank, an günstigen Stellen sind auch zwei bis drei Britz-

bänke ausgebildet

c $0,10 \mathrm{~m} \quad$ Humoser Lößlehm

d $\quad 0,20-0,30 \mathrm{~m}$ Brauner Lößlehm mit welliger Untergrenze

e $0,40-0,50 \mathrm{~m}$ Gelber Löß

f ca. $0,05 \mathrm{~m}$ Steinige Zone mit kleinen Schieferstückchen und Bimsbröckchen

g $0,10-0,20 \mathrm{~m} \quad$ Grauer Löß

h $0,60-0,80 \mathrm{~m}$ Horizontal-streifiger, geschichteter Basalt-Tuff, abwechselnd mit dünnen Lößlagen. Von der Unterseite der Schicht $g$ ausgehend, reichen Eiskeile in den Tuff.

In der Sickergrube waren darunter folgende Sedimente kurze Zeit aufgeschlossen, so daß sie nur flüchtig beobachtet werden konnten:

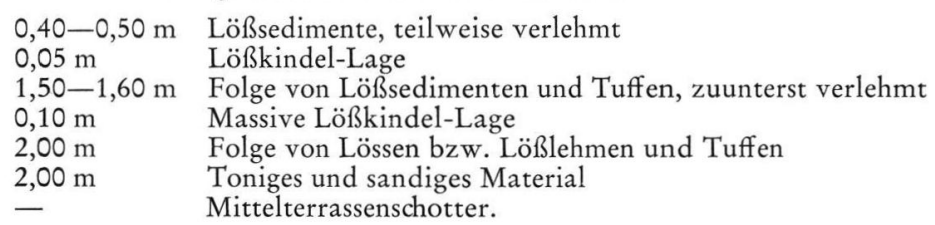

Die Fundschicht liegt 0,25-0,30 m unter der Bims-Unterkante. Da sie eine andere Neigung als die allerödzeitliche Oberfläche unter dem Bims hat, liegt die Fundschicht teilweise im braunen Lößlehm, teilweise im gelben Löß. Die Magdalénienfunde gehören in die Zeit der Lößanwehung vor dem Beginn des Alleröd.

Der den Fundplatz überdeckende allerödzeitliche Bims hat die Fundschicht vor Abtragung und Verwitterung bzw. Entkalkung geschützt, so daß das Knochenmaterial erhalten blieb; außerdem wurde die Zerstörung der Siedlungsreste durch den Pflug verhindert.

Im Mai/Juni 1968 wurde westlich des Neubaus eine $30 \mathrm{~m}^{2}$ große Fläche untersucht, die durch den Bau einer Begrenzungsmauer akut gefährdet war. Z. Z. (Oktober 1968) sind wir dabei, eine im Juli begonnene Untersuchung eines $66 \mathrm{~m}^{2}$ großen Areals südlich des Hauses im Bereich des zukünftigen Vorgartens abzuschließen.

Der Siedlungsplatz war mit einer Plattenlage bedeckt. Die Platten sind in erster Linie aus Schiefer, der in der näheren Umgebung ansteht. Daneben kommen Quarzit- und Quarzgerölle, die aus Rheinschottern stammen, und Basaltlava vor. Zwischen den Steinen der Plattenlage wurden zahlreiche Tierknochen gefunden. In erster Linie - etwa $90 \%$

1) Kurzfassung eines Vortrags, gehalten auf der Tagung der Deutschen Quartärvereinigung am 7. 8. 1968 in Biberach a. d. Riß. 
handelt es sich um Wildpferdreste. Ferner sind vor allem Mammut, Ren und Rind sowie eine größere Anzahl von Vogelknochen (Schneehuhn ?) vorhanden. (Vorläufig an der Grabungsstelle bestimmt.)

Die Plattenlage stellt den eigentlichen Siedlungshorizont der altsteinzeitlichen Jäger dar. Nach dem Abräumen der Platten und Tieferlegen der Fläche um 0,10 m kam ein breitovaler Grundriß einer Behausung mit einem größten Durchmesser von etwa $6 \mathrm{~m}$ zum Vorschein. Im Innern dieser Behausung - wohl eines Zeltes - fanden wir zahlreiche Gruben. Die Grubeninhalte waren unterschiedlich. In einigen Gruben lagen lediglich Artefakte und Tierknochen; in einer Grube lag eine Perlenkette aus fast $40 \mathrm{Holz}$ perlen sowie mehreren durchbohrten Tierzähnen. Die Perlen der Kette befanden sich teilweise noch im ursprünglichen Verband.

Auf dem Boden einer anderen Grube lagen angebrannte Tierknochen und eine größere, aus Rengeweih geschnitzte „Venus“-Figur. Außer den Gruben kamen zwei Feuerstellen, die größere sorgfältig aus Quarzgeröllen in einer schüsselförmigen Einfassung aus Basaltlava gesetzt, zum Vorschein. Die von I. Peters durchgeführte Holzbestimmung ergab Birke und Kiefer.

Steinwerkzeuge wurden sehr reichlich gefunden. Neben dem örtlich vorkommenden Süßwasserquarzit wurde auch der ortsfremde Feuerstein, der über eine größere Entfernung eingetauscht worden sein muß, verarbeitet. Unter den Werkzeugen dominieren deutlich die Stichel. Gut vertreten sind Rückenmesserchen und Bohrer. Kratzer treten dagegen auffällig zurück.

Geräte aus Elfenbein und Knochen sind gut belegt. Die Knochenspitzen haben eine ein- oder beidseitig abgeschrägte Basis und manchmal eine „Blutrille“. Während Knochennadeln gut belegt sind, sind Harpunen bisher nur durch einen abgebrochenen Widerhaken vertreten. Steinwerkzeuge und Knochengeräte verweisen den Fundplatz Gönnersdorf in das Spätmagdalénien.

Unter den Schmuckgegenständen sind an erster Stelle - weil sonst kaum erhalten Holzperlen zu nennen. Die meisten Stücke gehören zu der bereits erwähnten Perlenkette. Die Holzperlen sind kugelig, scheibenförmig, zylindrisch, schuhleistenförmig oder annähernd rechteckig. Zu den Schmuckgegenständen gehören ferner zahlreiche durchbohrte Zähne - meist von Fuchs oder Wolf - sowie Anhänger aus Elfenbein.

Eine Überraschung war das Auffinden zahlreicher Kunstwerke. Am häufigsten sind „Venus“-Figuren, die bisher zehnmal als Schnitzereien aus Elfenbein, Geweih oder Knochen und mehr als $100 \mathrm{Mal}$ als Gravierungen auf Schieferplatten gefunden wurden. Stets sind die Figuren in der schematisch-stilisierenden Art des späten Jungpaläolithikums ausgeführt. Meist sind die Gestalten einzeln dargestellt, doch kommen auch Paarungsszenen und Szenen mit zwei Frauen vor. Zahlenmäßig geringer vertreten sind Gravierungen von Tieren. In erster Linie handelt es sich um Ritzungen von Mammut und Wildpferd. Seltener sind Darstellungen von Wildrind, Wollnashorn und Rentier.

Manuskr. eingeg. 9. 10. 1968.

Anschrift des Verf.: Dr. G. Bosinski, 5 Köln, Weyertal 125, Institut für Ur- und Frühgeschichte. 